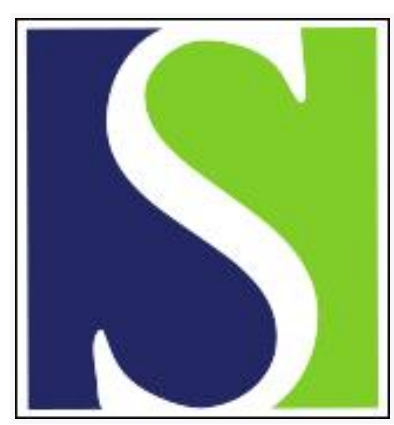

Scand J Work Environ Health 1997;23(6):435-439

https://doi.org/10.5271/sjweh.266

Issue date: Dec 1997

Deficiencies of the Stockholm vascular grading scale for hand-arm vibration

by Palmer KT, Coggon DN

The following article refers to this text: 2001;27 suppl 1:1-102

Key terms: raynaud's phenomenon; vascular; workshop

This article in PubMed: www.ncbi.nlm.nih.gov/pubmed/9476807

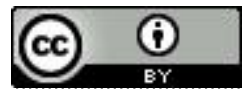




\title{
Deficiencies of the Stockholm vascular grading scale for hand-arm vibration
}

\author{
by Keith T Palmer, MFOM, ${ }^{1}$ David N Coggon, FRCP'
}

\author{
Palmer KT, Coggon DN. Deficiencies of the Stockholm vascular grading scale for hand-arm vibration. Scand $J$ \\ Work Environ Health 1997;23(6)435-9.
}

Objectives The internationally accepted Stockholm vascular grading scale for vibration white finger (VWF) has shortcomings that have received insufficient attention; some of its key descriptors require further definition and, more crucially, the scale does not suit all possible patterns of symptoms. To determine whether these shortcomings matter in practice, an attempt was made to apply the Stockholm vascular scale to 92 consecutive cases of VWF assessed by one area office of the Health and Safety Executive in the United Kingdom.

Methods Case definition was based on clinical history and examination, but blanching was confirmed from observations of 34 men ( $37 \%$ of the cases). The 145 affected hands were graded under 2 alternative definitions of "frequent attacks"; and the 92 persons were graded using the same definitions according to the extent of blanching in their worse affected hand.

Results Depending on the choice of definition of frequent attacks, between $36 \%$ and $61 \%$ of the affected hands fell outside the scale and were unclassifiable. Thirty percent of the individual cases could not be classified under either definition, and $28 \%$ altered their grading according to the definition. The findings were broadly similar when the analysis was restricted to the 34 cases with observed blanching.

Conclusions It was concluded that the Stockholm vascular scale does not encompass the full range of disease and that its grading is highly sensitive to different interpretations of "frequent attacks". Alternative approaches to clinical grading are required.

Key terms Raynaud's phenomenon, workshop, vascular.

Since vibration white finger (Raynaud's phenomenon secondary to hand-arm vibration) was first described, there have been several proposals for the clinical grading of the condition. In the 1970s Taylor \& Pelmear devised a popular system that incorporated information on the extent of blanching, the presence or absence of neurological symptoms, and the effect of the disorder on work and leisure activities (1).

Griffin proposed an alternative scale based on the extent of blanching alone (2). This scale allotted points according to the phalanges affected, and the points were then summed to give a total for each hand. Inherent was the assumption that underlying severity is reflected by area of involvement, rather than by the frequency of attacks (which can be influenced by external "nondisease" factors such as climate and time spent out-ofdoors).

In the $1980 \mathrm{~s}$ an international meeting of vibration experts met in Stockholm and proposed the third and now widely accepted Stockholm grading scale (3). Their proposal actually comprised 2 scales that separated the vascular and neurological effects of vibration. It was introduced, in part, because difficulty had been encountered in differentiating between stages 2 and 3 on the Taylor-Pelmear scale. The vascular scale is reproduced in table 1.

Table 1. Stockholm Workshop scale for the classification of coldinduced Raynaud's phenomenon in the hand-arm vibration syndrome.

\begin{tabular}{lll}
\hline Stage & Grade & Description \\
\hline 0 & Mild & $\begin{array}{l}\text { No attacks } \\
\text { Occasional attacks affecting only the tips of one } \\
\text { Or more fingers }\end{array}$ \\
2 & Moderate & $\begin{array}{l}\text { Occasional attacks affecting distal and middle } \\
\text { (rarely also proximal) phalanges of one or more } \\
\text { fingers }\end{array}$ \\
3 & Severe & $\begin{array}{l}\text { Frequent attacks affecting all phalanges of most } \\
\text { fingers }\end{array}$ \\
4 & Very severe & $\begin{array}{l}\text { As in stage 3, with trophic skin changes in the } \\
\text { finger tips }\end{array}$ \\
\hline
\end{tabular}

1 Medical Research Council Environmental Epidemiology Unit, University of Southampton, Southampton General Hospital, Southampton, United Kingdom.

Reprint requests to: Dr Keith Palmer, Medical Research Council Environmental Epidemiology Unit, University of Southampton, Southampton General Hospital, Southampton SO16 6YD, UK. [e-mail: krp@mrc.soton.ac.uk] 
The Stockholm scale has become the accepted standard for clinical grading, but insufficient attention has been given to its shortcomings. Clearly, expressions such as "occasional attacks", "frequent attacks", and "most fingers" need to be defined before cases can be unambiguously classified, although researchers who use the scale seldom report their definitions. Moreover, the scale does not suit all possible patterns of symptoms. For example, it is unclear how one should classify a person with frequent attacks affecting only the tips of the fingers.

To determine whether these shortcomings are important in practice, we have attempted to apply the Stockholm scale to a consecutive series of vibration white finger (VWF) cases identified and assessed by one local area office of the Health and Safety Executive (HSE) in the United Kingdom over the period between 1991 and 1995.

\section{Subjects and methods}

In the United Kingdom employers have a statutory obligation to report suspected cases of VWF to the HSE. Between 1991 and 1995 HSE's Employment Medical Advisory Service interviewed and systematically assessed all such reports from the counties of Hampshire, Berkshire, Dorset, Wiltshire, and the Isle of Wight. The Service also conducted 5 cross-sectional surveys in the industries that gave rise to reports. Ninety-four cases of VWF were confirmed, among 48 public utility workers, 17 quarrymen, 16 stonemasons, 7 foresters, and 6 local authority workers, chiefly engaged in highway repair.
Two of the men (1 utility worker and 1 quarryman) were unable to describe the distribution of their disease and therefore were excluded from this analysis. The remaining sample included 8 retired workers. All the subjects were male, with a median age of 46 (range 19-66) years and a mean exposure time of 19 (range 3 -42) years.

All the cases were interviewed by a physician or nurse, who completed a questionnaire and examination similar to that proposed by the Faculty of Occupational Medicine (4). The questionnaire inquired about the frequency of symptoms and contained hand diagrams on which the respondents shaded the affected areas and thus permitted grading on the Stockholm vascular scale. Case definition was based solely on clinical history and examination, but the diagnosis was supported by observed blanching (usually following a simple cold provocation challenge test) in $37 \%$ of the cases.

Of the 92 cases, 53 had bilateral symptoms and 39 had symptoms in 1 hand only. Among the 34 men with observed blanching, 27 had bilateral symptoms, and 7 had a unilateral complaint. The severity of the vascular symptoms was scored for each affected hand, with certain assumptions about disease extent and disease frequency.

\section{Disease extent}

"Most fingers" was interpreted as 3 or more digits in the affected hand; "1 or more fingers" was interpreted literally, and was therefore compatible with attacks in any or all digits on the affected hand.

Where blanching affected different digits to a different extent, the extent of disease in the worst affected digit was adopted as the basis for the score.

Table 2. Classification of vascular symptoms in 145 hands affected by blanching, according to the first definition of frequent attacks. a

\begin{tabular}{|c|c|c|c|c|c|c|c|c|}
\hline \multirow{4}{*}{$\begin{array}{l}\text { Extent of involvement of worst affected } \\
\text { digit }\end{array}$} & \multicolumn{8}{|c|}{ Digits and frequency } \\
\hline & \multicolumn{4}{|c|}{$1-2$ digits affected } & \multicolumn{4}{|c|}{$3-5$ digits affected } \\
\hline & \multicolumn{2}{|c|}{$\begin{array}{l}\text { Monthly } \\
\text { attacks }\end{array}$} & \multicolumn{2}{|c|}{$\begin{array}{l}\text { Attacks less } \\
\text { frequent }\end{array}$} & \multicolumn{2}{|c|}{$\begin{array}{l}\text { Monthly } \\
\text { attacks }\end{array}$} & \multicolumn{2}{|c|}{$\begin{array}{l}\text { Attacks less } \\
\text { frequent }\end{array}$} \\
\hline & $N$ & $\%$ & $N$ & $\%$ & $\mathrm{~N}$ & $\%$ & $N$ & $\%$ \\
\hline \multicolumn{9}{|l|}{ Distal phalanx } \\
\hline Unclassifiable & 16 & 11.0 & .. &.. & 12 & 8.3 & .. & .. \\
\hline Class $1^{\mathrm{b}}$ &.. & .. & 3 & 2.1 & $\cdot$. & $\cdot$. & 2 & 1.4 \\
\hline \multicolumn{9}{|l|}{ Distal and middle phalanges } \\
\hline Unclassifiable & 20 & 13.8 & .. &.. & 23 & 15.9 & .. & .. \\
\hline Class $2^{b}$ & .. &. & 9 & 6.2 &.$\cdot$ & .. & 11 & 7.6 \\
\hline \multicolumn{9}{|l|}{ Distal, middle and proximal phalanges } \\
\hline Unclassifiable & 18 & 12.4 & .. & .. &.. & .. & .. & .. \\
\hline Class $2^{b}$ & .. & .. & 2 & 1.4 & .. & .. & 7 & 4.8 \\
\hline Class $3^{b}$ & .. &.. &.. &.. & 22 & 15.2 & .. & .. \\
\hline \multicolumn{9}{|l|}{ All phalanges and trophic changes } \\
\hline Unclassifiable & - & - & - & - &.. & .. & - & - \\
\hline Class $4^{b}$ & .. &.$\cdot$ & .. & .. & - & - &.. & .. \\
\hline
\end{tabular}

a Frequent = attacks occurring once a month or more often at cold times of the year; occasional = anything less than frequent and more than zero.

b Corresponding Stockholm grade. 
Table 3. Classification of vascular symptoms in 145 hands affected by blanching, according to the second definition of frequent attacks. ${ }^{a}$

\begin{tabular}{|c|c|c|c|c|c|c|c|c|}
\hline \multirow{4}{*}{$\begin{array}{l}\text { Extent of involvement of worst affected } \\
\text { digit }\end{array}$} & \multicolumn{8}{|c|}{ Digits and frequency } \\
\hline & \multicolumn{4}{|c|}{$1-2$ digits affected } & \multicolumn{4}{|c|}{$3-5$ digits affected } \\
\hline & \multicolumn{2}{|c|}{$\begin{array}{c}\text { Daily } \\
\text { attacks }\end{array}$} & \multicolumn{2}{|c|}{$\begin{array}{l}\text { Attacks less } \\
\text { frequent }\end{array}$} & \multicolumn{2}{|c|}{$\begin{array}{l}\text { Daily } \\
\text { attacks }\end{array}$} & \multicolumn{2}{|c|}{$\begin{array}{l}\text { Attacks less } \\
\text { frequent }\end{array}$} \\
\hline & $N$ & $\%$ & N & $\%$ & $\mathrm{~N}$ & $\%$ & N & $\%$ \\
\hline \multicolumn{9}{|l|}{ Distal phalanx } \\
\hline Unclassifiable & 6 & 4.1 & .. & & 8 & 5.5 & .. & \\
\hline Class $1^{b}$ & .. &.. & 7 & 4.8 & .. & .. & 13 & 9.0 \\
\hline \multicolumn{9}{|l|}{ Distal and middle phalanges } \\
\hline $\begin{array}{l}\text { Unclassifiable } \\
\text { Class } 2^{\mathrm{b}}\end{array}$ & $\begin{array}{r}12 \\
. .\end{array}$ & 8.3 & $\ddot{17}$ & 117 & 15 & 10.3 & ... & 124 \\
\hline \multicolumn{9}{|l|}{ Distal, middle and proximal phalanges } \\
\hline Unclassifiable & 11 & 7.6 &. & .. & .. & .. & .. & \\
\hline Class $2^{b}$ & .. & .. & 9 & 6.2 & & .. & 11 & 7.6 \\
\hline Class $3^{b}$ & .. & .. & .. & .. & 18 & 12.4 & .. & .. \\
\hline \multicolumn{9}{|l|}{ All phalanges and trophic changes } \\
\hline Unclassifiable & - & - & - & - & .. & .. & - & - \\
\hline Class $4^{b}$ & & .. & .. & .. & - & - & .. & .. \\
\hline
\end{tabular}

a Frequent $=$ attacks occurring at least daily at cold times of the year; occasional $=$ anything less than frequent and more than zero.

${ }^{b}$ Corresponding Stockholm grade.

\section{Disease frequency}

To test how grading is influenced by the definition of attack frequency, "frequent" attacks were defined in 2 alternative ways, either as "attacks occurring at least once a month at cold times of the year" or as "attacks occurring at least daily at cold times of the year". In each case "occasional" attacks then became "anything less than frequent and more than zero".

In addition, the subjects were graded according to the extent of blanching in their worse affected hand. The prevalence of unclassified disease and the impact of different definitions of attack frequency were assessed. These analyses were repeated for the subset of men who had observed blanching.

Finally, to examine the relation between frequency and extent, we calculated unweighted and weighted scores of disease extent for each affected person and plotted them against attack frequency according to the 2 definitions of "frequent". The unweighted score of disease extent was derived by allocating 1 point for each affected phalanx and summing the scores over both hands. The weighted score applied the weighting scale proposed by Griffin (2), again with scores summed over both hands to determine the total.

\section{Results}

Tables 2 and 3 show the extent of disease and frequency of symptoms in the affected hands. Under the first definition of frequency (frequent $=$ "attacks occurring at
Table 4. The Stockholm vascular grading of 92 affected workers, based on extent of blanching in their worse affected hand and two alternative definitions of frequent attacks.

\begin{tabular}{lcccc}
\hline $\begin{array}{l}\text { Stockholm grading } \\
\text { according to second } \\
\text { definition of } \\
\text { frequent attacks }\end{array}$ & \multicolumn{4}{c}{$\begin{array}{c}\text { Stockholm grading according to first definition } \\
\text { of frequent attacks }\end{array}$} \\
\cline { 2 - 5 } & 1 & 2 & 3 & $\begin{array}{l}\text { Unclas- } \\
\text { sifiable }\end{array}$ \\
\hline 1 & 5 & - & - & 8 \\
2 &.. & 20 & 3 & 15 \\
3 &.. &.. & 13 & $\frac{13}{28}$ \\
Unclassifiable &.. &. &.. & 28 \\
\hline
\end{tabular}

a Frequent = attacks occurring once a month or more often at cold times of the year; occasional = anything less than frequent and more than zero. b Frequent = attacks occurring at least daily at cold times of the year; occasional $=$ anything less than frequent and more than zero.

least once a month at cold times of the year", table 2), 89 of the 145 affected hands $(61 \%)$ were unclassifiable. Alternatively, following the second definition (frequent = "attacks occurring at least daily at cold times of the year", table 3), 52 hands (36\%) fell outside the categories defined by the Stockholm scale.

Table 4 illustrates the effect that different definitions of "frequent" had on the grading. Thirty-eight cases (41\% of the sample) were allotted the same Stockholm grade whichever definition was adopted, but for 26 men (28\%) the grade varied according to the definition of "frequent" (including 23 men who were unclassifiable under the first definition, but became classifiable under the second). Twenty-eight men (30\%) could not be classified under either definition.

The descriptor of grade 2 in the Stockholm scale allows for occasional attacks that affect the whole finger 

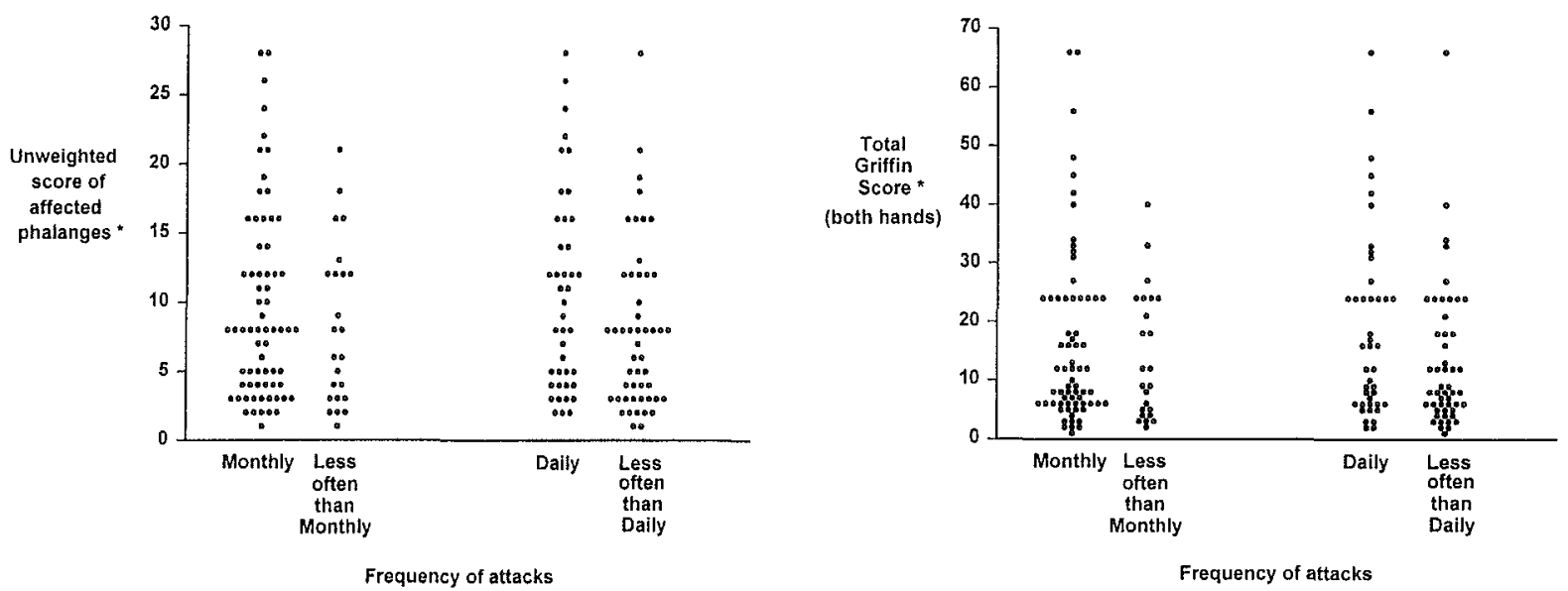

Figure 1. Relation between extent and frequency of blanching in 92 affected workers. [ ${ }^{*}=$ the unweighted score was the number of phalanges affected on both hands; the total Griffin score was the sum of the Griffin scores for both hands (see text)]

but states that the extent only "rarely" encompasses the proximal phalanx. However, blanching of this extent was reported by 8 of 20 men with a score of grade 2 according to the first definition of "frequent" and 18 of the 38 with a score of grade 2 with the second definition. Had the "rare case" assumption not been made, they too would have been unclassifiable.

The findings were broadly similar when these analyses were repeated for subjects with observed blanching. It was not possible to classify $31(51 \%)$ of the affected hands under the first definition of attack frequency or 18 $(30 \%)$ of the hands under the second definition. Among the 34 affected men, $8(24 \%)$ could not be classified under either definition of attack frequency, and for 7 $(21 \%)$ the grades were switched when the definition varied. The proximal involvement in grade 2 disease occurred in 6 of 9 cases so graded under the first definition of frequent attacks and in 8 of 18 cases scored as grade 2 according to the second definition.

The omission of certain combinations of extent and frequency from the Stockholm scale (such as low extenthigh frequency and high extent-low frequency), appears to imply that the 2 variables are highly correlated. However, in our sample, there was substantial overlap in the extent of disease between men with different frequencies of attack (figure 1).

\section{Discussion}

Our findings indicate that the Stockholm vascular scale does not encompass the full range of disease, that grading is highly sensitive to alternative interpretations of disease frequency, and that unwarranted assumptions may have been made about the relation between the extent and frequency of disease in affected persons.
Our data derive from a case series defined by clinical history and examination. There was no opportunity to corroborate the diagnoses or measure the maximum extent of blanching using objective tests, but we do not believe this missing information invalidates the principal conclusions. The success of such tests is often measured against clinical opinion as the gold standard; in our series blanching was observed by a physician in $37 \%$ of the cases, and grading difficulties were similarly evident for these men. Moreover, in clinical practice grading scales are often applied to cases diagnosed only from reported symptoms.

The pattern of disease in our sample could have been so unusual as to preclude generalization of the conclusions, but this possibility seems unlikely. Reported cases of VWF may differ in severity from those that go unreported, but most of the present series (85\%) was identified in cross-sectional surveys of the workplaces from which index reports arose, and the participation rates in these investigations all exceeded $80 \%$. The cases came from several different industries and involved several different categories of vibrating tool known to be important in disease occurrence. We consider therefore that similar grading difficulties would arise in many common occupational health settings.

These shortcomings are undesirable in epidemiologic research and have other practical implications. In the United Kingdom, the Health and Safety Executive recommends that workers who have stage 3 disease avoid further exposure and that consideration should be given to the limitation of exposure for those at grade 2 whose disease is progressing rapidly (5), but it is in the distinction of disease between stages 2 and 3 that the scale is most deficient.

How could grading be improved? A better approach might be to separate disease frequency from disease ex- 
tent. The data in figure 1 suggest that no strong relation exists between the two. Therefore, no clear basis exists for reporting them in combination. In epidemiologic research a clear separation would be advantageous. Frequency of attack, as the Stockholm workshop recognized, depends on time spent out-of-doors, glove wearing, and other factors that relate to cold exposure. Thus disease of a given inherent severity will manifest a different attack frequency depending on climate, latitude, and cultural habit. In comparisons of international research findings, extent of disease can be considered a more stable and perhaps a more desirable index of severity. By contrast, in clinical and medicolegal practice, where the need is to assess the impact of disease on individual persons, information on attack frequency is desirable.

Improvements in grading may come with the development of objective measurement tools, but meanwhile a more complete description of the patterns of digit involvement in VWF and their relation to attack frequency would be helpful. A score based on area of involvement (weighted or unweighted) provides a simple, unambiguous scheme for research purposes, while a frequency subscript can be added where relevant.

\section{Acknowledgments}

We are grateful to Dr Granville Crane for making this data set available to us and to Leslie Styles and Denise Gould for their help in preparing the manuscript.

\section{References}

1. Taylor W, Pelmear PL. Vibration white finger in industry. London: Academic Press, 1975.

2. Griffin MJ. Handbook of human vibration. London: Academic Press, 1990:573-5.

3. Gemne G, Pyykkö I, Taylor W, Pelmear PL. The Stockholm Workshop scale for the classification of cold-induced Raynaud's phenomenon in the hand-arm vibration syndrome (revision of the Taylor Pelmear scale). Scand J Work Environ Health 1987;13:275-8.

4. Faculty of Occupational Medicine of the Royal College of Physicians. Hand-transmitted vibration: clinical effects and pathophysiology, part 1: report of a working party [appendix A2]. London: Royal College of Physicians, 1993.

5. Health and Safety Executive (HSE). Hand-arm vibration. London: HSE, 1994. HS(G)88.

Received for publication: 30 May 1997 